\title{
ANÁLISE RETROSPECTIVA DOS MOTIVOS DOS DEMISSIONÁRIOS DA ÁREA DA ENFERMAGEM DE UM HOSPITAL GERAL
}

\author{
Liana Lautert ${ }^{15}$ \\ Márcia Ziebell Ramos \\ Desireé Luzardo Cardozo Bianchessi"
}

\begin{abstract}
Resumo: Na presente investigação, revisamos as fichas de desligamento do pessoal de enfermagem de um hospital geral de Porto Alegre, cujos desligamentos ocorreram no período de abril de 1992 à abril de 1993. Os motivos de desligamentos expressos nas fichas de desligamento tiveram seu conteúdo analisado. Verificamos que os motivos expressos pelos enfermeiros são distintos dos relacionados pelos auxiliares de enfermagem e não foi significativa a relação entre os motivos das demissões e as características da área de trabalho.
\end{abstract}

UNITERMOS: Enfermagem - Trabalho - Rotatividade

\section{INTRODUÇÃO}

Segundo Ferreira (1986:1695) o trabalho é "a aplicação das forças e faculdades humanas para alcançar um determinado fim". Logo, ele constitui uma atividade fundamental do ser humano, possibilitando-lhe a construção do mundo e reconhecer-se naquilo que faz, ao transformar a natureza em um produto para sua utilidade. E, o exercício sistemático da aplicação de forças e faculdades humanas, constitui o ofício, a profissão.

A partir dessa premissa, podemos concluir que o trabalho deve constituir uma atividade que é, ao mesmo tempo, prazerosa e um meio de sobrevivência na sociedade. Assim, o trabalho é uma condição inerente a vida humana e the dá sentido.

Hoefel (1992:260) afirma que essa condição do trabalho é constatada quando verificamos "a tentativa de apropriação que o sujeito faz, no sentido de concretizar projetos, ser útil, ter uma profissão".

No entanto, com o desenvolvimento acelerado das demandas sociais, constatamos que 0 trabalho esta se tornando, cada vez mais compartimentalizado, e o indivíduo não consegue mais identificar-se naquilo que realiza. É uma época caracterizada por um consumo desenfreado, que

\footnotetext{
${ }^{15}$ Professora Assistente do DEMC - Escola de Enfermagem - UFRGS; Doutoranda em Psicologia - Psicólogas do Serviço de Psicologia do Hospital de Clínicas de Porto Alegre.
} 
pressiona o ser humano no sentido de ter coisas, fazendo com que aumente o consumo e, conseqüentemente, sua produção. Essas características refletemse em todos os segmentos, inclusive no trabalho que é realizado dentro das instituições hospitalares, onde o paradigma da tecnologia exige profissionais cada vez mais especializados, produzindo uma divisão técnica e social do trabalho.

Ao analisarmos a institucionalização da enfermagem, observamos que segue esse mesmo princípio. Cabe ao pessoal de enfermagem, que atua a nível hospitalar, a realização do cuidado, produzindo um serviço na área da saúde. Neste processo de trabalho são aplicados modelos de atenção à saúde de forma estratificada e hierarquizada, reproduzindo a forma de organização da administração dos cuidados de enfermagem. Essa hierarquia é representada pelos profissionais que compõe a equipe: a enfermeira, o técnico de enfermagem e o auxiliar. Dentro desse contexto, trabalhadores, cuja grande maioria pertence ao gênero feminino, desenvolvem sua profissão pressionados por um lado, pelo avanço da tecnologia e por outro pelas condições que dispõe para desenvolver o trabalho dentro das instituições.

Considerando esses pressupostos, desenvolvemos a presente investigação trabalhando com os individuos demissionários da equipe de enfermagem para pesquisarmos o seguinte problema: Quais são os motivos que levam o profissional da equipe de enfermagem a sair da instituição? Para tanto, estabelecemos os objetivos a seguir:

\section{Objetivos}

- Realizar o levantamento dos motivos dos desligamentos do pessoal de enfermagem de um hospital geral, de grande porte, de Porto Alegre, que ocorreram no período de abril de 1992 à abril de 1993.

- Verificar o tempo de serviço em que ocorre maior incidência de desligamentos do pessoal de enfermagem.

- Correlacionar os motivos dos desligamentos com, as características da área de trabalho, quanto a áreas abertas ou fechadas.

- Estudar a correlação entre alguns motivos mencionados pelos demissionários e a existência ou não de adaptação ao trabalho.

\section{REFERENCIAL TEÓRICO}

Historicamente o trabalho vem sendo discutido nos campos da adminıstração, socıologia. poiitica, economia e, mais recentemente, na área da psicologia; pois constitui o meı pelo qual são produzidos os bens e serviços na sociedade. O desempenho do individuo tem particular interesse, quando nos preocupamos com a forma como o trabalho é desenvolvido.

Sabemos que o interesse e a aptidão são individuais e variam de acordo com as diferentes experiências de vida do indivíduo, bèm como, de suas crenças, valores e características psicológicas, levando-o a procurar um trabalho que melhor preencha suas necessidades. 
Verificamos, no entanto, que este fato nem sempre pode ser contemplado devido a necessidade premente do individuo para sustentar a si e a sua familia, fator que o conduz à busca de um trabalho que lhe garanta o sustento. Deste modo, a condição econômica, impondo-lhe a urgência de uma forma de sustento, o faz optar por um trabalho que nem sempre é uma escolha voluntária, o qual constitui, muitas vezes, apenas uma fonte de renda para o trabalhador, não satisfazendo suas necessidades de realização e, conseqüentemente, ele não possui a motivação necessária para desempenhar sua função satisfatoriamente.

Werther e Davis (1983, p.314) conceituam a motivação como sendo "o impulso de uma pessoa de agir porque ela assim o deseja" ou como o esforço e tenacidade exercidos pela pessoa para fazer ou alcançar algo, como afirma Chiavenatto (1992:153). Stoner (1985: 300) amplia esse conceito afirmando que o impulso, além de causar e canalizar, "sustenta c comportamento das pessoas". De acordo com essas afirmativas, uma pessoa que não está motivada ao realizar uma tarefa, terá um desempenho pouco satisfatório. Além disso o ambiente de trabalho como qualquer outro ambiente social, apresenta fenômenos que, para indivíduos predispostos, podem ser sentidos como agressões.

Couto (1981:16) cita alguns prejuizos para as instituições, decorrentes da insatisfação no trabalho. O autor menciona que "indivíduos insatisfeitos, principalmente os mais qualificados, executam mal o trabalho, gastando mais tempo com menos precisão e desperdício de material". Outras características que podem ser observadas, são: o absenteismo, aumento da incidência de doenças e acidentes de trabalho.

Essas questões preocupam os homens há milhares de anos, a medida em que necessitam selecionar pessoas para realizarem determinadas tarefas. Logo, foram sendo criadas, através dos anos, técnicas para selecionar adequadamente cada indivíduo de acordo com o trabalho que teria que executar. Dessa forma, procuramos selecionar as pessoas mais adequadas para cada atividade, de acordo com alguns critérios básicos pré estabelecidos.

Dejours (1987) estudando a psicopatologia do trabalho, examinou as características das vivências subjetivas dos trabalhadores, nos seus ambientes de trabalho ou seja, como eles percebiam esse ambiente, fator que influencia na adaptação ou não à atividade. Pitta (1991), partindo desse pressuposto, e considerando o paradigma do trabalho hospitalar, estudou a natureza do trabalho dentro do hospital, a partir da ótica centrado no conteúdo de um trabalho que tem a dor e a morte como ofício, a fim de analisar como ele acontece, visto suas particularidades.

O trabalho dentro de uma instituição hospitalar tem aspectos próprios relacionadas à "características ambíguas entre uma mítica religiosa/canitativa e as regras gerais de mercado" como destaca Pitta (1991:42). Associada a essa ambigüidade encontramos o avanço tecnológico produzindo uma divisão técnica e social, cada vez maior no trabalho.

No que se refere a essa questão, Kurcgant (1991:23) afirma que 
considerando o seroiço de enfermagem como um grupo organizado de pessoas, onde é grande o número, a complexidade e a dioersidade das atioidades realizadas, é eoidente a necessidade da dioisăo do trabalbo entre os seus elementos, bem como o estabelecimento do padrăo dos relaçöes entre eles.

Desta forma, estabeleceu-se um modelo piramidal onde as funções técnicas mais qualificadas ficam ao encargo dos enfermeiros, os quais chefiam e supervisionam os auxiliares de enfermagem que executam as tarefas menos qualificadas, prescritas pelos primeiros.

\section{Variáveis que influenciam no desempenho de um trabalho}

Há milhares de anos vem sendo propostos testes para seleção de pessoal, visando a melhor adequação possivel do homem a atividade que vai executar, a fim de obter o melhor rendimento. As práticas de seleção de pessoal remontam a Platão e se modernizaram muito, a medida em que as empresas começaram a se preocupar com o que pensam seus colaboradores e ver os resultados concretos, derivados de uma seleção criteriosa de pessoas.

Mas, como disse muito bem Chiavenatto (1992:167), "cada individuo ingressa e permanece em uma empresa se ele acredita que isso pode leva-lo ao alcance de determinados objetivos pessoais". Frente a essa possibilidade, nossa preocupação centra-se em conhecer os fatores que levam o indivíduo a desinteressar-se pelo trabalho, para que possamos intervir, auxiliando-o.

A seleção adequada de cada indivíduo, para o preenchimento de um cargo, propicia à organização satisfazer seus objetivos, bem como, o trabalhador estando bem adaptado, representa uma fonte de renda e um meio para que ele satisfaça suas necessidades. E, de acordo com a atividade a ser desenvolvida, são traçadas algumas características consideradas necessárias ao trabalhador que irá desempenha-la, a fim de adequar-se melhor ao cargo. Kurcgant (1991:97) compartilha dessa mesma teoria, a medida em que refere que

$$
\begin{aligned}
& \text { particularmente na enfermagem, pela peculiaridode profissional, o processo seletioo } \\
& \text { necessita ser entendido como o primeiro ponto, quando pensamos em desenooloer } \\
& \text { pessoal dentro de uma proposta que aceita esse aspecto como importante para } \\
& \text { garantia de uma assistência de boa qualidade. }
\end{aligned}
$$

No entanto, apesar da sofisticação cada vez maior das técnicas de seleção e recrutamento de pessoal, existem algumas variáveis que influenciam o desempenho satisfatório dos indivíduos, causando insatisfação. A motivação é uma delas, e Stoner (1985:300) descreve que ela "é curiosa porque os motivos não podem ser observados ou medidos diretamente, necessitando ser inferidos do comportamento humano" e Chiavenato (1992:154) complementä lembrando que "as diferenças individuais entre as pessoas dificultam enormemente a 
definição de parâmetros universais que as empresas possam utilizar para motivar as pessoas em igualdade de condições".

Werther e Davis (1983) citam algumas causas relacionadas ao próprio trabalho como geradoras de tensão no emprego, tais como: a sobrecarga de trabalho e os horários a cumprir, os quais, segundo o autor, podem estar relacionados diretamente com a má qualidade da supervisão. Eles citam ainda o clima político inseguro na empresa, a retro informação de desempenho insuficiente, a autoridade inadequada ante as responsabilidades, a ambigüidade de papéis, frustrações, conflitos interpessoais e inter grupais, diferenças entre os valores da empresa e os dos empregados e mudariças de qualquer tipo.

Cada vez mais os estudiosos preocupam-se com o trabalhador. Couto (1981) realizou um levantamento dos fatores agressivos ao trabalhador onde destacou-se em ordem de importância: a forma da organização administrativa, - relacionamento interpessoal deficiente, correlação inadequada entre capacidade, responsabilidade e salário e problemas de motivação.

Stoner (1985) realizou uma classificação diferente desses fatores, subdividindo-os em "características do trabalho" que referem-se aos atributos inerentes a tarefa e as "características da situação do trabalho", que constituem as políticas de pessoal, recompensa e clima da organização e o relacionamento com colegas e chefes. Bianchi (1990:96), investigando o estresse de enfermeiros que trabalham em centro cirúrgico, concluiu que ele "é agravado em situações nas quais existe atribuição de responsabilidade e, ao mesmo tempo, há uma limitação do poder necessário ao seu cumprimento", ou seja, o problema decorre das características da situação do trabalho. Dejours (1987:69) comentando sobre as características da situação do trabalho, afirma que

as frustraçōes resultantes de um conteúdo significatioo inadequado as potencialidades $e$ as necessidades de personalidade, podem ser ume fonte de grandes esforços de adaptaşăo. Mesmo as más condiçōes de trabalbo săo, no conjunto, menos temíoeís do que ume organizascăo de trabalbo rígida e imutáoel.

Werther e Davis (1983:397) citam também as causas fora do emprego que causam tensão, quais sejam: preocupação financeira, problemas com filhos, problemas físicos e ou conjugais e mudança de residência. À essas causas Stoner (1985) denomina características individuais, relacionadas diretamente com o indivíduo, às quais acrescenta o comportamento necessário do indivíduo, para conseguir um desempenho ótimo - percepção do papel. Segundo os autores, podem ser resumidas em três, as variáveis pessoais que influenciam o desempenho de um individuo, quais sejam: a capacidade física e intelectual do individuo, a hierarquia de suas necessidades, sua expectativa ou a percepção do papel que irá desempenhar na instituição. 
Outro fator que influencia na satisfação do trabalhador é a idade. Segundo Werther e Davis (1983) existem numerosas razões responsáveis pela satisfação das pessoas a medida em que envelhecem, entre as quais podemos destacar a própria experiência que o indivíduo vai adquirindo, fazendo com que se ajuste à situação de trabalho. Bianchi (1990) cita que o indivíduo com idade entre 28 e 32 anos, e que tem um desempenho profissional entre 5 e 7 anos, costuma passar por um período de inquietação. Essa, por sua vez pode leva-lo a mudar de emprego ou até de atividade.

O tamanho da organização também esta relacionado com a satisfação no trabalho. Werther e Davis (1983:313) afirmam que

"es grandes organizaçóes tendem a oprimir as pessoas e perhurbar os processos de apoio (...) os empregados comeşam a sentir que estäo perdendo o controle das eoentos que as afetam, porque o poder de decisăo se distanciou muito deles. 0 ambiente de trabalbo também perde elementos de proximidode pessoal. amizade. equipe de trabalbo de pequeno grupo (...)".

A escolha da área de trabalho e ou treinamento e ou experiência anterior, são fatores que tem correlação significativa com o nível de satisfação do trabalhador na empresa e, Bianchi (1990) evidenciou que o nivel de estresse dos enfermeiros que participaram da amostra de sua investigação, também está correlacionado com estes fatores.

\section{Potenciais conseqüências organizacionais da rotatividade de pessoal.}

As conseqüências da rotatividade podem ser tanto negativas quanto positivas para a empresa. Mobley (1992) refere como conseqüências negativas, principalmente, o custo para a empresa e cita algumas pesquisas que computaram os custos que acarretam uma demissão. $O$ autor cita os custos de recrutamento gastos com publicidade; os de seleção gastos com entrevistas, provas, checagem de referências, aplicação de testes e custos administrativos correlatos. Os custos com a admissão incluem exames médicos; os de instrução referem-se a orientação, treinamento formal e prático no trabalho, tempo do treinador e queda na produtividade de outras pessoas, quando de um recém chegado. Mobley (1992) lembra ainda o fato de que não há pesquisas que captem a qualidade do empregado que se desliga ou do seu substituto, e acrescenta que "se o funcionário que deixa a empresa tem bom desempenho ou se é um mau funcionário, o verdadeiro custo e conseqüências para a organização certamente diferem" . (id.1992:34)

Outras conseqüências negativas citadas por Mobley (1992) referem-se a queda do nível de desempenho quando houve o desligamento de um indivíduo de grande potencial, a queda nos padrões sociais de comunicação, a queda do moral dos que ficam na organização frente a percepção da saída dos outros; quando são utilizadas estratégias indiferenciadas de controle, acarretando 
informações insuficientes de causas e conseqüências e gerando soluções inapropriadas.

As conseqüências positivas relacionadas ao desligamento de pessoal, referem-se ao afastamento de empregados de baixo desempenho, redução de conflitos, inovação, flexibilidade e adaptabilidade quando os recém admitidos trazem consigo "novos conhecimentos, idéias abordagens, tecnologias $e$ estilos" (Mobley, 1993:42). Como sintetiza muito bem o autor (1992: 50-3)

\footnotetext{
" progredir em direşăo à compreensăo dos consequiêncías do turnooer e à integraşăo desse compreensăo a um gerenciamento maís efetioo do fenômeno exige um desenooloimento maís profundo de a menos duos áreas. Primeiro, săo necessários pesquises adicionais, conceituaís e empiricas, para especificar as conseqüêncios indioiduais, organizacionais e societais... Segundo, é preciso baoer um maior desenooloimento da tecnología de contabilizaşăo e mensuraçăo de recursos bumanos para que as oários consequiêncios positioas e negatioos possam ser integrados em algum tipo de indexador de utilidade liquida".
}

Após essa breve exposição, consideramos que conhecendo alguns dos fatores que interferem na perfeita adaptação do trabalhador à atividade que irá desenvolver, é possivel intervir junto ao trabalhador, a fim de favorecer sua adaptação. Werther e Davis (1983:410) recomendam o aconselhamento como forma de intervir, auxiliando o trabalhador a adaptar-se ao ambiente de trabalho, o qual consiste na "discussão de um problema com o empregado a fim de ajuda-lo a enfrentar a situação da melhor maneira possível". Desse modo, segundo os autores, é possivel superar eventuais problemas, restabelecendo a confiança e re-ordenando o trabalhador e reduzindo as conseqüências negativas do desligamento de individuos potencialmente positivos para a organização.

Somos da opinião de que as organizações deveriam ser bem informadas no sentido de acompanharem os contingentes desde o ingresso do profissional na organização, de modo a ter um vislumbre maior do processo de turnover e do próprio desenvolvimento da carreira do indivíduo. Deste modo, acompanhando e investindo no trabalhador, certamente o nivel de satisfação aumentará e, conseqüentemente, o desempenho profissional.

\section{METODOLOGIA DA INVESTIGAÇÃO}

Essa investigação constitui um estudo de caracter exploratório e descritivo, realizado a partir das fichas de desligamento de pessoal (Anexo II), utilizadas pelo Serviço de Psicologia da instituição em foco.

Campo de ação: A presente investigação desenvolveu-se em uma instituição hospitalar de grande porte, localizada na cidade de Porto Alegre. 
Populaçăo alvo: A população da presente investigação foi composta por enfermeiros e auxiliares de enfermagem que trabalhavam na referida instituição, a qual está distribuída por serviços, como segue:

Tabela 1: Distribuição do pessoal de enfermagem segundo o local de trabalho

\begin{tabular}{|c|c|c|c|c|c|c|}
\hline \multirow[b]{2}{*}{$\begin{array}{l}\text { Local de } \\
\text { trabalho }\end{array}$} & \multicolumn{2}{|c|}{ Enfermeiras } & \multicolumn{2}{|c|}{ Aux de Enfermagem } & \multicolumn{2}{|c|}{ TOTAL } \\
\hline & $f$ & $\%$ & $f$ & $\%$ & $f$ & $\%$ \\
\hline SESP & 17 & 6,99 & 34 & 3,07 & 51 & 3,77 \\
\hline SEEM & 18 & 7,40 & 49 & 4,42 & 67 & 4,96 \\
\hline SECC & 30 & 12,34 & 242 & 21,86 & 272 & 20,15 \\
\hline SEC & 39 & 16,05 & 177 & 15,99 & 216 & 16,00 \\
\hline SEM & 80 & 32,94 & 324 & 29,28 & 404 & 29,93 \\
\hline SEMI & 59 & 24,28 & 281 & 25,38 & 340 & 25,19 \\
\hline$\Sigma$ & 243 & 100 & 1107 & 100 & 1350 & 100 \\
\hline
\end{tabular}

LEGENDA: SESP = Servico do Enfermagem em Saúdo Pública; SEEM = Servico do Enfermegem em Emergencia; SECC = Serviço de Enfermagem em Centro Cirúrgico; SEC = Serviço de Enfermagem Cirúrgica; SEM = Servico de Enfermagem Modica - SEMI = Servico de Enfermagem Meterno Infantil

Amostra: A amostra desta investigação foi constituída por todos os enfermeiros e auxiliares de enfermagem demissionários, no período de abril de 1992 à abril de 1993, perfazendo um total de 26 (vinte e seis) enfermeiros, os quais constituíram 10,69\% do total de enfermeiros da instituição e 94 (noventa e quatro) auxiliares de enfermagem, constituindo $8,49 \%$ do quadro de pessoal dessa categoria.

Instrumento de investigaçåo: Utilizamos as fichas de entrevistas de desligamento, padronizadas pelo Senviço de Psicologia da instituição, onde desenvolvemos a investigação. Estas fichas são compostas por um cabeçalho onde constam os dados de identificação do demissionário, seguido pelo motivo de desligamento expresso pelo demissionário na entrevista. No verso deste instrumento estão algumas questões referentes a pesquisa de opinião dos demissionários (Anexo II).

Método para coleta de dados: Revisamos todas as fichas de desligamento do pessoal de enfermagem do hospital da investigação, cujos desligamentos ocorreram no período de abril de 1992 à abril de 1993. As fichas, utilizadas nesta investigação, foram preenchidas pelos psicólogos e estagiários de psicologia pertencentes ao Serviço de Psicologia da instituição, no momento da entrevista de desligamento do pessoal. Detivemo-nos nas informaçōes referentes ao tempo que o demissionário trabalhava na instituição, área de atuação, categoria profissional, motivos da demissão, nas questōes relevantes da pesquisa de opinião e sugestões. Os motivos das demissões, expressos nas fichas de desligamento, tiveram seu conteúdo analisado e foram agrupados por semelhança semântica, estabelecendo-se categorias. Analisamos 
separadamente os motivos expressos pelos enfermeiros e pelos auxiliares de enfermagem.

\section{APRESENTAÇÃO E ANÁLISE DOS DADOS DA INVESTIGAÇÃO}

Tabela 2: Distribuição da freqüência dos enfermeiros e auxiliares de enfermagem demissionários, conforme o serviço de origem.

\begin{tabular}{|c|c|c|c|c|c|c|}
\hline \multirow{2}{*}{$\begin{array}{l}\text { Serviço de } \\
\text { Enfermagem }\end{array}$} & \multicolumn{2}{|c|}{ Enfermeiros } & \multicolumn{2}{|c|}{ Aux. de Enfermagem } & \multicolumn{2}{|c|}{ TOTAL } \\
\hline & I & $\%$ & $f$ & $\%$ & $f$ & $\%$ \\
\hline SEC & 04 & 15,38 & 12 & 12,76 & 16 & 13,33 \\
\hline SECC & 01 & 3,84 & 20 & 21,28 & 21 & 17,50 \\
\hline SEM & 10 & 38,48 & 29 & 30,87 & 39 & 32,50 \\
\hline SEMI & 09 & 34,61 & 19 & 20,21 & 28 & 23,33 \\
\hline SEEM & 02 & 7,69 & 07 & 7,44 & 09 & 7,50 \\
\hline SESP & - & - & 01 & 1,06 & 01 & 0,83 \\
\hline ltem náo preenchido & - & - & 06 & 6,38 & 06 & 5,00 \\
\hline$\Sigma$ & 26 & 100 & 94 & 100 & 120 & 100 \\
\hline
\end{tabular}

$\mathrm{Na}$ tabela 2 verificamos uma maior distribuição dos demissionários pertencentes ao Serviço de Enfermagem Médica, no ano 1992/1993. No entanto, quando analisamos o percentual de desligamento em relação ao quadro de pessoal do senviço, verificamos que a percentual maior de desligamentos de enfermeiros, ocorreu no Serviço de Enfermagem Materno Infantil, representando $15,25 \%$ do quadro de pessoal deste serviço, seguido pelo SEM com $12,50 \%$ do quadro. Entre os auxiliares de enfermagem demissionários, tiveram maior freqüência de distribuição no SEEM com $14,28 \%$ do quadro de pessoal, seguido pelo SEM, com $8,95 \%$ do quadro

As taxas de tumover desta instituição podem ser consideradas baixas se levarmos em conta a afirmação de Roesch (in Mobley, 1992:16) de que "no Brasil, as taxas de tumover são altas, representando cerca de cinqüenta porcento do pessoal ocupado". Um fator o qual consideramos influir na baixa rotatividade do pessoal, é o porte da organização, visto que organizações maiores podem ter mais oportunidades de mobilidade interna, processos mais sofisticados de seleção de pessoal e sistemas de compensação mais competitivos, conforme também coloca Mobley (1992). Por outro lado, nas organizaçōes de grande porte são comuns os problemas de comunicação, baixa coesão grupal e maior despersonalização e burocratização.

$\mathrm{Na}$ presente instituição, verificamos que, dadas as características do trabalho a ser desenvolvido e preocupados com a sua qualidade, é processada uma seleção bastante criteriosa dos candidatos ao trabalho ali desenvolvido, bem como, o acompanham durante seu desligamento, a fim de analisar e 
contribuir para a produção de conhecimentos e de discussão dos aspetos que compõe as condições de trabalho da categoria profissional da área da saúde.

Tabela 3: Distribuição da freqüência da idade dos enfermeiros e auxiliares de enfermagem demissionários, na época de seu desligamento.

\begin{tabular}{|c|c|c|c|c|c|c|}
\hline \multirow[t]{2}{*}{ Faixa etária } & \multicolumn{2}{|c|}{ Enfermeiros } & \multicolumn{2}{|c|}{ Aux. de Enfermagem } & \multicolumn{2}{|c|}{ Total } \\
\hline & $f$ & $\%$ & $f$ & $\%$ & f & $\%$ \\
\hline $181-25$ anos & 04 & 15,38 & 11 & 11,40 & 15 & 12,50 \\
\hline $261-35$ anos & 16 & 61,55 & 41 & 43,64 & 57 & 47,51 \\
\hline $361-45$ anos & 02 & 7,69 & 28 & 29,79 & 30 & 25,00 \\
\hline $461-55$ anos & - & - & 05 & 5,31 & 05 & 4,16 \\
\hline Item năo preenchido & 04 & 15,38 & 09 & 9,57 & 13 & 10,83 \\
\hline & 26 & 100 & 94 & 100 & 120 & 100 \\
\hline
\end{tabular}

Nesta tabela verificamos a grande incidência de demissionários na faixa etária entre 26 e 35 anos, tanto na amostra de auxiliares de enfermagem quanto de enfermeiros, perfazendo um total de cinqüenta e sete indivíduos, dado que representa $47,51 \%$ do total de demissionários da área de enfermagem, no período 1992/1993. Bianchi (1990) cita que o indivíduo com idade entre 28 e 32 anos, e que tem um desempenho profissional entre 5 e 7 anos, costuma passar por um período de inquietação. Essa, por sua vez pode leva-lo a mudar de emprego ou até de atividade.

$\mathrm{Na}$ tabela a seguir (4), verificamos a grande incidência de demissionários com tempo de serviço até um ano $(42,34 \%)$. Nestas demissões estão incluídas as decorrentes dos contratos para cobertura de licença gestação, as quais totalizaram $15,37 \%$ das enfermeiras demissionárias (quatro enfermeiras).

Tabela 4: Distribuição da freqüência do tempo de serviço dos enfermeiros demissionários.

\begin{tabular}{|c|c|c|c|c|c|c|}
\hline \multirow{3}{*}{$\begin{array}{l}\text { Tempo de } \\
\text { Servico }\end{array}$} & \multirow{2}{*}{\multicolumn{2}{|c|}{$\begin{array}{l}\text { Pedido de } \\
\text { demissão }\end{array}$}} & \multicolumn{2}{|c|}{ D. sem justa causa } & \multicolumn{2}{|c|}{ Total } \\
\hline & & & $f$ & $\%$ & $f$ & $\%$ \\
\hline & $f$ & $\%$ & & & & \\
\hline até 12 meses & 09 & 34,66 & 02 & 7,69 & 11 & 42,34 \\
\hline $11-2$ anos & 05 & 19,23 & - & - & 05 & 19,23 \\
\hline $21-4$ anos & 03 & 11,53 & - & - & 03 & 11,53 \\
\hline $41-6$ anos & 02 & 7,69 & 01 & 3,84 & 03 & 11,53 \\
\hline $61-8$ anos & 01 & 3,84 & - & - & 01 & 3,84 \\
\hline $81-10$ anos & - & - & - & - & - & $=$ \\
\hline $10 \longmapsto-13$ anos & 01 & 3,84 & 01 & 3,84 & 02 & 7,69 \\
\hline $13 \longmapsto-16$ anos & - & & 01 & 3,84 & 01 & 3,84 \\
\hline$\Sigma$ & 21 & 80,79 & 05 & 19,21 & 26 & 100 \\
\hline
\end{tabular}


Observando o percentual de desligamentos com o tempo de serviço de até dois anos, verificamos que $61,57 \%$ dos enfermeiros demissionários possuíam este tempo de serviço na instituição, ou seja, pouco tempo de serviço. Não podemos esquecer que neste índice estão computadas as demissões de enfermeiros que foram contratados temporariamente para cobertura de licenças de gestação.

O fator tempo é amplamente discutido pela literatura como desencadeante de demissões, visto que a rotatividade é significativamente maior entre empregados com pouco tempo de serviço. As demissões dos enfermeiros são em sua grande maioria voluntárias $(80,79 \%)$.

Tabela 5: Distribuição da freqüência do tempo de serviço dos auxiliares de enfermagem demissionários.

\begin{tabular}{|c|c|c|c|c|c|c|}
\hline \multirow[b]{2}{*}{ Tempo de Serviço } & \multicolumn{2}{|c|}{ Pedido de demissão } & \multicolumn{2}{|c|}{ D. sem justa causa } & \multicolumn{2}{|c|}{ Total } \\
\hline & $f$ & $\%$ & $f$ & $\%$ & $f$ & $\%$ \\
\hline até 12 meses & 09 & 9,59 & 15 & 15,95 & 24 & 25,54 \\
\hline 11 - 2 anos & 09 & 9,59 & 04 & 4,25 & 13 & 13,84 \\
\hline $21-4$ anos & 07 & 7,45 & 18 & 19,20 & 25 & 26,64 \\
\hline $41-6$ anos & 05 & 5,31 & 05 & 5,31 & 10 & 10,62 \\
\hline $61-8$ anos & 01 & 1,06 & 02 & 2,12 & 03 & 3,18 \\
\hline 81 - 10 anos & - & - & 04 & 4,25 & 04 & 4,25 \\
\hline $101-13$ anos & 05 & 3,31 & 05 & 3,31 & 10 & 10,62 \\
\hline $131-16$ anos & - & $\cdots$ & 04 & 4,25 & 04 & 4,25 \\
\hline $161-19$ anos & - & - & 01 & 1,06 & 01 & 1,06 \\
\hline$\Sigma$ & 36 & 38,31 & 58 & 61,69 & 94 & 100 \\
\hline
\end{tabular}

Nos dados apresentados na tabela 5 ocorre o mesmo fenômeno observado com os enfermeiros, ou seja, a grande incidência de demissionários auxiliares de enfermagem com tempo de serviço de até um ano, incluindo as demissões decorrentes das coberturas de licenças de gestação. No entanto, ocorreram somente dois desligamento ao término da licença gestação $(2,12 \%)$ do total de desligamentos com tempo até um ano de trabalho. Verificamos também que a prevalência de demissionários até quatro anos é grande, perfazendo um total de $65,95 \%$ dos demissionários auxiliares de enfermagem no período 1992/1993. Mobley (1992:122) refere que "dois terços a três quartos dos desligamentos ocorrem até o final dos três primeiros anos de serviço"; destes $50 \%$ acontecem até o final do primeiro ano. $O$ autor também comenta que não foi possivel ainda associar o nível de instrução com o desligamento, no entanto dados biográficos do indivíduo são úteis para previsão do turnover.

Roesch (in Mobley,1992:16) afirma que no Brasil, "70\% das demissões relacionam-se ao turnover involuntário", dado que observamos nos demissionários auxiliares de enfermagem, onde perfazem um total de $61,69 \%$ dos demissionários. 
motivo indisciplina tem a maior prevalência na tabela 6 , com um total de $27,38 \%$ dos motivos. Nesta categoria foram incluidos os problemas de conduta, tais como: negligência, faltas e atestados, falta de interesse pelo trabalho, falta de postura profissional e falta de cooperação. $O$ absenteísmo foi incluído na categoria indisciplina pois o consideramos gerador da mesma, a medida em que o demissionário protelava seu desligamento não comparecendo ao trabalho, gerando descontentamento e sobrecarga na equipe.

Tabela 6: Distribuição da freqüência dos motivos constantes nas fichas de desligamento dos auxiliares de enfermagem demissionários.

\begin{tabular}{|c|c|c|c|c|c|c|c|c|}
\hline \multirow[b]{2}{*}{ Motivos } & \multicolumn{2}{|c|}{$\begin{array}{l}\text { Pedidos de } \\
\text { demissão }\end{array}$} & \multicolumn{2}{|c|}{$\begin{array}{l}\text { D. s/justa causa } \\
\text { funcionário }\end{array}$} & \multicolumn{2}{|c|}{$\begin{array}{c}\text { D. s/justa causa } \\
\text { chefia }\end{array}$} & \multicolumn{2}{|c|}{$\begin{array}{l}\text { Total dos } \\
\text { motivos }\end{array}$} \\
\hline & $f$ & $\%$ & $f$ & $\%$ & $f$ & $\%$ & $f$ & $\%$ \\
\hline Término L.G. & - & - & 02 & 2,17 & 02 & 2,22 & 04 & 1,79 \\
\hline Motivo pessoal & 12 & 29,26 & 11 & 11,75 & 04 & 4,44 & 27 & 12,10 \\
\hline Desenv. profis. & 06 & 14,63 & 01 & 1,17 & 03 & 3,33 & 10 & 4,48 \\
\hline Fator economico & 14 & 34,18 & 04 & 4,34 & 01 & 1,11 & 19 & 8,52 \\
\hline Relac. c/ chefia & 03 & 7,31 & 16 & 17,39 & 06 & 6,66 & 25 & 11,21 \\
\hline Clima trabalho & 02 & 4,87 & 09 & 9,78 & 14 & 15,55 & 25 & 11,21 \\
\hline Indisciplina & - & & 26 & 28,26 & 35 & 38,90 & 61 & 27,38 \\
\hline Falta capacid. & - & - & 19 & 20,65 & 25 & 27,79 & 44 & 19,74 \\
\hline Politica instituiç. & 04 & 9,75 & - & - & - & - & 04 & 1,79 \\
\hline S/carga trabalho & - & - & 01 & 1,17 & - & - & 01 & 0,44 \\
\hline Nâo cooperou & - & - & 02 & 2,17 & - & - & 02 & 0,88 \\
\hline Desconhece & - & - & 01 & 1,17 & - & - & 01 & 0,44 \\
\hline$\Sigma$ & 41 & 100 & 92 & 100 & 90 & 100 & 223 & 100 \\
\hline
\end{tabular}

Quando realizamos um cruzamento dos dados dessa tabela com os de tempo de serviço, verificamos que os auxiliares demissionários por indisciplina tinham de dois a quatro anos de serviço na instituição, dado que no gerou a pergunta: o que será que ocorreu a este pessoal que, após o período inicial de trabalho, tornou-se indisciplinado?

A falta de capacitação apareceu como segundo motivo, onde está incluída a dificuldade técnica e que o empregado não corresponde às expectativas do cargo. Do total de 44 motivos de desligamento por falta de capacitação, vinte e dois tinham tempo de serviço inferior a um ano, e treze demissionários trabalhavam dentro da empresa a quatro anos. Estes dados nos fizeram refletir sobre algumas questões tais como a possibilidade de treinar, investir no auxiliar de enfermagem que inicia a trabalhar na instituição uma vez que ele foi criteriosamente selecionado, fator que certamente reduziria muito o número de demissionários, visto o alto índice de desligamentos por esse motivo.

O terceiro motivo que se destacou nesta tabela foram os motivos pessoais, onde estavam incluídos problemas tais como: mudança de cidade, estudos, opção por outro tipo de trabalho, problemas familiares e de saúde. 
Em quarto lugar apareceram os motivos relacionados com a chefia $(11,21 \%$ dos motivos de desligamento) e clima de trabalho $(11,21 \%$ dos motivos). Estes referem-se, principalmente, ao relacionamento. A dificuldade de relacionamento com a chefia é citada maior número de vezes pelos auxiliares de enfermagem (19 vezes) do que pelas respectivas chefias (6 vezes). Já com o clima de trabalho acontece o inverso, é relatado mais pelas chefias, o que nos levou a inferir que 0 auxiliar de enfermagem, no período pré demissionário, por dificuldades de relacionamento, provavelmente gera um clima de trabalho insatisfatório.

Tabela 7: Distribuiçăo da freqüência dos motivos constantes nas fichas de desligamento dos enfermeiros demissionários.

\begin{tabular}{|c|c|c|c|c|c|c|c|c|}
\hline \multirow[b]{2}{*}{ Motivas } & \multicolumn{2}{|c|}{$\begin{array}{l}\text { Pedidos de } \\
\text { demissalo }\end{array}$} & \multicolumn{2}{|c|}{$\begin{array}{l}\text { D. SJusta causa } \\
\text { funcionário }\end{array}$} & \multicolumn{2}{|c|}{$\begin{array}{c}\text { D. s/usta causa } \\
\text { chefia }\end{array}$} & \multicolumn{2}{|c|}{$\begin{array}{l}\text { Total dos } \\
\text { motivos }\end{array}$} \\
\hline & $f$ & $\%$ & $f$ & $\%$ & $f$ & $\%$ & $f$ & $\%$ \\
\hline Témino L.C. & 02 & 4,54 & 02 & 4,54 & 02 & 4,54 & 06 & 13,63 \\
\hline Motivo pessoal & 03 & 6,81 & 01 & 2,27 & - & - & 04 & 9,09 \\
\hline Desenv. profís. & 03 & 6,81 & - & $\longrightarrow$ & - & - & 03 & 6,81 \\
\hline Fator económico & 05 & 11,36 & 01 & 2,27 & - & $\Longrightarrow$ & 06 & 13,63 \\
\hline Relac. of chefia & 01 & 2,27 & 01 & 2,27 & 03 & 6,81 & 05 & 11,36 \\
\hline Clima trabalho & 07 & 15,92 & - & - & 02 & 4,54 & 09 & 20,50 \\
\hline Indisciplina & - & - & - & - & 03 & 6,81 & 03 & 6,81 \\
\hline Polfitica instituig. & 04 & 9,09 & - & - & - & - & 04 & 9,09 \\
\hline Sicarga trabalho & 03 & 6,81 & - & - & - & - & 03 & 6,81 \\
\hline Nao cooperou & 01 & 2,27 & $\ldots$ & - & - & - & 01 & 2,27 \\
\hline$\Sigma$ & 29 & 65,92 & 05 & 11,36 & 10 & 22,72 & 4 & 100 \\
\hline
\end{tabular}

Na tabela 7 estão distribuídos os motivos expressos pelos enfermeiros, onde prevaleceu como motivo de solicitação de desligamento da empresa, o clima de trabalho. Nesta categoria foram incluídos problemas de relacionamento em geral, com colegas, sentimento de desvalorização e insatisfação com o clima de trabalho. Mobley (1992:120) cita a investigação realizada por Saleh, Lee e Prien os quais descobriram que "a falta de consideraçăo do supenvisor é a segunda razão mais freqüentemente citada para os desligamentos entre enfermeiras", evidenciando o quanto a baixa satisfação, aumenta a probabilidade de demissão.

A segunda categoria de motivos, foi o fator econômico onde foram incluídos a insatisfaçāo com o salário e realização de concurso público. Mobley (1992:113) comenta que o tumover muitas vezes é encorajado pela inflação "como meio de proteger os rendimentos", e isso esta evidente entre os fatores de desligamento dos enfermeiros, pois é reforçado pela realização de concurso público, que no Brasil assegura a estabilidade no emprego e, conseqüentemente, os rendimentos.

Outra categoria que apareceu em quatro solicitações de desligamentos, foi a política da instituição, na qual estavam incluídas as dificuldades em conciliar 
dois empregos e a falta de vaga na creche. O motivo licença de gestação refere-se àqueles demissionários que foram contratados pela empresa para cobertura de licença gestante e que, ao término desta, são desligados, caso não haja vaga definitiva para sua efetivação.

Analisando os motivos expostos pelos enfermeiros, concluímos que eles referem-se diretamente a auto realização pessoal e ou profissional.

\section{CONSIDERAÇÕES FINAIS}

O turnover é mais um processo contínuo do que um evento estático, envolvendo ações comportamentais cognitivas e afetivas, como evidenciamos nesta investigação.

Verificamos que a maior prevalência de demissionários auxiliares de enfermagem, ocorreu no período de tempo inferior a quatro anos de trabalho na instituição, com um total de $65,95 \%$ dos demissionários, enquanto que $61,57 \%$ dos enfermeiros desligaram-se da empresa com tempo de serviço inferior a dois anos e destes, $42,34 \%$ saíram antes de completar um ano. Tais achados vêm ao encontro do que afirma Mobley (1992) quando diz que cinqüenta porcento das demissões costumam ocorrer no primeiro ano de trabalho na empresa.

Analisamos, separadamente, os motivos dos desligamentos expressos pelos enfermeiros e auxiliares de enfermagem demissionários e observamos que os expressos pelos primeiros são distintos dos relacionados pelos auxiliares. Também, não foi significava a relação entre os motivos das demissões e as características da área de trabalho.

Constatamos que os motivos dos demissionários auxiliares de enfermagem, estão diretamente relacionados com o trabalho, tais como: indisciplina e falta de capacitação, sendo seguido pelo relacionamento inadequado com a chefia $\mathbf{e}$ clima de trabalho. Enquanto que os expressos pelos enfermeiros, referem-se a auto realização profissional ou pessoal, ou seja, o clima de trabalho na instituição favorecendo o desligamento destes profissionais, seguido pelo fator econômico, onde entrou a insatisfação com o salário e ou realização de concurso público.

Acreditamos que os dados encontrados nesta análise retrospectiva são bastante elucidativos, todavia não os consideramos substitutos de análises prognósticas, considerando a tendência dos indivíduos relatarem de forma seletiva e racionalizarem os motivos de seus desligamentos. Frente a essa problemática, resolvemos incluir na entrevista de desligamento, a pergunta: se houvesse oportunidade, você gostaria de voltar a trabalhar na empresa, futuramente? 


\section{SUGESTÕES}

Ao término desta investigação, apresentamos algumas sugestões que brotaram no decorrer deste trabalho, as quais pretendemos adotar e implementar. Entre elas destacamos:

- Realizar um trabalho conjunto entre o Serviço de Psicologia, o de seleção técnica de enfermagem e a unidade de destino do recém admitido, a fim de integra-lo adequadamente na empresa.

- Dar maior ênfase a escolha da área de interesse, tanto do auxiliar de enfermagem quanto da enfermeira, para evitar futuros problemas, culminando com o desligamento.

- Rever a política de ascensão profissional dentro da empresa, a fim de motivar o pessoal para o aperfeiçoamento.

- Valorizar o individuo quanto a sua especialização e formação técnica e não apenas quando assume algum cargo administrativo.

- Treinar e orientar o pessoal com falta de capacitação técnica, antes de demiti10.

- Realizar análises que sirvam de prognósticos dos futuros desligamento da empresa.

ABSTRACT: The present investigation has revised the nursing personnel leaving files at a general hospital in Porto Alegre. The data were collected between 1992 and 1993. The reasons for nurses dismissal or dropping-out are different among registered nurses and assistant nurses, however the study revealed that there have not been any significant relations between the working area and the reasons for personnel dismissing.

KEYWORDS: Nursing - Work - Turnover 


\section{ANEXO I: CATEGORIAS DOS MOTIVOS DE DESLIGAMENTO DO PESSOAL DE ENFERMAGEM}

1. LICENÇA GESTAÇÃO - Demissão após término da cobertura da licença de uma gestante, na área da enfermagem.

2. MOTIVOS PESSOAIS - Problemas familiares, de saúde, mudança de cidade, estudos, opção por outro tipo de trabalho, opção por não trabalhar, problema econômico (quando é muito dispendioso para comparecer ao trabalho).

3. DESENVOLVIMENTO PESSOAL - Oferta de trabalho na 'área da especialidade, insatisfação com o tipo de paciente ou unidade de trabalho, dificuldade de crescimento profissional/ promoção, falta de valorização profissional.

4. FATOR ECONÓMICO - Insatisfação com salário, concurso público.

5. RELACIONAMENTO COM A CHEFIA - Divergência de opinião entre o funcionário e a chefia, dificuldade de relacionamento com a chefia, hierarquia muito rígida.

6. CLIMA DE TRABALHO - Insatisfação com o clima de trabalho, sentimento de desvalorização, dificuldade de relacionamento em geral, dificuldade de relacionamento com os colegas.

7. INDISCIPLINA - Falta de postura profissional, de cooperação, negligência, indisciplina, atestados e faltas ao trabalho.

8. FALTA DE CAPACITAÇÃO - Dificuldade técnica, não corresponde às expectativas do cargo (falta de capacidade. de integração).

9. POLITICAS DA INSTITUIÇÃO - Dificuldades para conciliar dois empregos (sobrecarga na instituição e ou pessoal), falta de vaga na creche.

10. SOBRECARGA DE TRABALHO - Excesso de trabalho na instituição.

11. NÃO COOPEROU NA ENTREVISTA.

12. DESCONHECE O MOTIVO. 
Nome:

Idade:

Data:

Função:

Instrução:

Setor de trabalho:

Admissão:

Salário:

O funcionário

foi demitido

Demissão:

pediu demissão

Motivo:

Motivo de saída expresso na entrevista:

OPINIÕES SOBRE O SALÁRIO

$\square$ Superior a outros locais

$\square$ Adequado

DInferior a outros locais

$\square$ Insatisfatório

$\square$ Não tem dados

QUANTIDADE DE TRABALHO
$\square$ Demasiada
$\square$ Adequada
$\square$ Variável
$\square$ Pouca

RELACIONAMENTO COM OS COLEGAS

$\square$ Satisfeito

$\square$ Contato superficial

$\square$ Motivo de insatisfação

$\square$ Insatisfeito

$\square$ Não tem dados suficientes

\section{OPINIŌES SOBRE A ORGANIZAÇÃO} HOSPITAL

$\square$ Satisfeito

$\square$ Motivo de insatisfação

$\square$ Insatisfeito

$\square$ Não tem dados
TREINAMENTO INICIAL

$\square$ Chefia

$\square$ Chefia e colega

$\square$ Colega

$\square$ Iniciativa própria

$\square$........

\section{OPINIŌES SOBRE O CARGO}

$\square$ Atribuição de acordo com o cargo

$\square$ Atribuição não estava de acordo com cargo

$\square$...

\section{RELACIONAMENTO COM A CHEFIA}

$\square$ Satisfeito

$\square$ Contato superficial

$\square$ Motivo de insatisfação

$\square$ Insatisfeito

$\square$ Não tem dados suficientes

POSSIBILIDADE DE CARREIRA

$\square$ Hospital oferece possibilidade

$\square$ Há possibilidade porem não seguem critérios na atribuição das promoçōes

$\square$ Não há possibilidade de promoção

$\square$ Dentro do cargo não há como ser promovido

$\square$ Não tem dados

$\square$.

BENEFÍCIOS AOS FUNCIONÁRIOS
Existem? $\quad \square$ Sim $\quad \square$ Não
Quais?
O que falta?

SUGESTŌES:

PARECER DO ENTREVISTADOR 


\section{REFERÊNCIAS BIBLIOGRÁFICAS}

1. BIANCHI, Estela Regina._Estresse em enfermagem: análise da atuação do enfermeiro em centro cirúrgico. Tese de Doutorado em Enfermagem na Universidade de São Paulo, 1990.

2. CHIAVENATTO, Idalberto. Gerenciando pessoas. O passo decisivo para administração participação. São Paulo: Makron Books, 1992.

3. COUTO, Hudson de A. Fadiga psíquica: Resultado da aplicação de um método alternativo para identificação dos agentes etiológicos ligados ao ambiente hospitalar. R. Bras. de Saúde Ocupacional. n.36, v.9, out.,nov., dez., 1981.

4. DEJOURS, C. A loucura do trabalho: estudo de psicopatologia do trabalho. 2. ed. São Paulo: Cortez/Oboré, 1987.

5. FERREIRA, Aurélio B. de H. Novo dicionário da língua portuguesa. 2 ed. Rio de Janeiro: Nova Fronteira, 1986.

6. HOEFEL, Maria da Graça et al. Perfil de saúde PROCEMPA. Porto Alegre: Grupo Laboro, 1992.

7. KURCGANT, Paulina "et al". Administração em enfermagem. São Paulo: E.P.U., 1991.

8. MOBLEY, William H. Turnover. Causas, conseqüências e controle. Porto Alegre: Ortiz, 1992.

9. PITTA, Ana. Hospital - Dor e morte como ofício. 2 ed. São Paulo: Hucitec, 1991.

10. STONER, James A.F. Administração. 2 ed. Rio de Janeiro: Prentice Hall, 1985.

10. WERTHER, William B., DAVIS, Keith. Administração de pessoal e recursos humanos. São Paulo: McGraw-Hill, 1983. 